\title{
Non-invasive evaluation of cardiac index by impedance cardiography in patients undergoing percutaneous nephrolithotomy
}

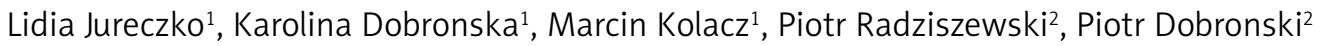

\author{
${ }^{1} 1^{\text {st }}$ Department of Anesthesiology and Intensive Care, Medical University of Warsaw, \\ Warsaw, Poland \\ ${ }^{2}$ Department of Urology, Medical University of Warsaw, Warsaw, Poland
}

Submitted: 21 March 2016

Accepted: 23 June 2016

Arch Med Sci 2018; 14, 4: 801-806

DOI: https://doi.org/10.5114/aoms.2016.63598

Copyright $\odot 2016$ Termedia \& Banach

\section{Abstract}

Introduction: Percutaneous nephrolithotomy (PNL) is an endoscopic treatment of renal lithiasis. It is usually two-staged: it begins in the lithotomy position for ureteral catheter placement and retrograde pyelography, and subsequently an optimal renal access is obtained in the prone position. Some patients under epidural anesthesia do not tolerate the prone position and the PNL cannot be continued. This may be related to changes occurring within the circulatory system. The aim of this prospective randomized double-blind study was to evaluate the changes of the cardiac index $(\mathrm{Cl})$ during PNL.

Material and methods: In a group of 50 patients, with ASA physical status grade $1-2$, epidural anesthesia with either $0.2 \%$ ropivacaine or $0.25 \%$ bupivacaine was performed and then the $\mathrm{Cl}$ was evaluated by impedance cardiography.

Results: Forty-five patients were included in the analysis; all tolerated the PNL well. After turning prone, a decrease in the $\mathrm{Cl}$ was always recorded, a maximum after $10-15 \mathrm{~min}-22.58 \pm 11.47 \%$. There was significant variability of recorded values. The average $\mathrm{Cl}$ dropped from $2.96 \pm 0.42 \mathrm{l} / \mathrm{min} / \mathrm{m}^{2}$ to $2.28 \pm 0.39 \mathrm{l} / \mathrm{min} / \mathrm{m}^{2}$. In 7 patients the decrease in the $\mathrm{Cl}$ was greater than $35 \%$. No correlation was observed with the arterial blood pressure or the heart rate. The decrease in the $\mathrm{Cl}$ occurred irrespective of the type of local anesthetic used $(p=0.91)$.

Conclusions: A decrease in the $\mathrm{Cl}$ was observed in every case, and it should be taken into consideration during qualification for PNL in the prone position.

Key words: epidural anesthesia, regional anesthesia, prone position.

\author{
Corresponding author: \\ Karolina Dobronska MD \\ $1^{\text {st }}$ Department \\ of Anesthesiology \\ and Intensive Care \\ Medical University \\ of Warsaw \\ 4 Lindleya St \\ 02-005 Warsaw, Poland \\ Phone: +48 501323534 \\ E-mail: karolinapladzyk@ \\ gmail.com
}

\section{Introduction}

Urinary stone disease is one of the most common ailments of the urinary tract. Its incidence depends on various factors including diet, region, climate, race/ethnicity, gender and genetics. The prevalence rates vary from $1 \%$ to $20 \%$, and it is higher in countries with a high standard of life. For some areas, an increase of more than $37 \%$ over the last 20 years has been reported [1].

Renal stones should be treated actively in the case of growth, de novo formation, obstruction, associated infection and acute or chronic pain. The stone size exceeding $20 \mathrm{~mm}$ is also an indication for percutaneous nephrolithotomy (PNL), if observation is not an option. Comorbidity and 
patient's preference need to be taken into consideration when making treatment decisions. Recently, the indications for open or laparoscopic stone surgery have significantly decreased. Most complex stones, including partial and complete staghorn stones, should be approached primarily with PNL, which remains the standard procedure for large renal calculi [1].

Percutaneous nephrolithotomy is usually twostaged. It begins in the lithotomy position for cystoscopic placement of the ureteral catheter and retrograde pyelography and, subsequently, a patient is placed mainly in the prone position for percutaneous access and stone removal. This position offers more options for puncture.

In most centers, PNL is done under general anesthesia (GA). General anesthesia is associated with a risk of complications due to putting an intubated, muscle-relaxed, unconscious patient in a prone position. Other complications, including blood transfusion, nausea and vomiting or fever, are more often observed after general than after regional anesthesia; the cost of general anesthesia is also higher [2]. Regional anesthesia that can be performed independently for PNL includes spinal, epidural or combined spinal-epidural blocks. A segmental epidural block is better than spinal anesthesia in terms of hemodynamic stability, postoperative analgesia, patient's satisfaction and reduced incidence of postoperative nausea and vomiting [3]. Epidural anesthesia takes longer to act than spinal anesthesia, but it allows one to avoid the motor block so the patient can change the position from lithotomy to prone himself with a little assistance. The position of a patient should not be changed rapidly immediately after the spinal anesthesia has been performed, due to the risk of too high anesthesia level and hemodynamic complications.

At the Department of Urology, where the research has been conducted, around 185 PNL procedures take place every year; $85 \%$ of them are performed under epidural anesthesia. If there are contraindications for this technique, GA is performed.

Clinical observations prove that certain patients do not tolerate the prone position during the second stage of PNL. After some time, they present decompensated cardiac insufficiency: dyspnea, bradycardia and hypotension. This may be related to changes occurring within the circulatory system, which involve a decrease in the cardiac output (CO). Cardiac output is the volume of blood pumped by the heart per minute and is the product of the heart rate and stroke volume (SV). Cardiac output and its value calculated per body mass, namely the cardiac index $(\mathrm{Cl})$, are among the most important parameters for cardiac func- tion monitoring, providing an estimate of whole body perfusion oxygen delivery. They may also provide important information in order to guide early hemodynamic support $[4,5]$.

The present study evaluates the $\mathrm{Cl}$ variability during PNL. Percutaneous nephrolithotomy is a minimally invasive procedure; the incision of the skin is small and, during anesthesia, basic monitoring is applied. Impedance cardiography (ICG) was chosen as a safe, simple, inexpensive and non-invasive method of hemodynamic monitoring. It enabled the assessment of hemodynamic parameters in real time, with immediate reading of the results and repetition of the measurements in optional time intervals [6]. This method is based on measuring the electrical bioimpedance of the thorax. Four pairs of electrodes are attached to the skin of the patient. This allows an analysis of the CO with each heartbeat and is well tolerated by the patient.

\section{Material and methods}

The aim of this prospective randomized double-blind study was to evaluate the changes of the $\mathrm{Cl}$ in patients undergoing PNL; the data were collected after local bioethical committee approval. After obtaining written informed consent, 50 patients, ASA grade 1-2, men and women, planned for the PNL procedure under epidural anesthesia, were randomly assigned (1:1), according to a computer-generated randomization list with permuted blocks (block sizes of two to four).

The exclusion criteria were the patient's refusal, allergy to local anesthetics, contraindications for epidural anesthesia, pregnancy, weight $<30 \mathrm{~kg}$ or $>155 \mathrm{~kg}$, and height $\langle 120 \mathrm{~cm}$ or $>230 \mathrm{~cm}$. The patients were allocated to two groups using a randomization table ( $n=25$ each). Two different local anesthetics were used for the epidural block: group $M$ : $0.25 \%$ bupivacaine with epinephrine 1 : 200000 (Marcaine 0.25\% Adrenaline, AstraZeneca), group R: $0.2 \%$ ropivacaine (Naropin $0.2 \%$, AstraZeneca). In both groups, a $10 \mu \mathrm{g}$ of sufentanil was added epidurally (Sufenta, Janssen-Cilag).

After admission to the operating room, an intravenous access was established and the patient received a drip infusion of $500 \mathrm{ml}$ of $0.9 \%$ sodium chloride with an antibiotic ( $2^{\text {nd }}$ generation cephalosporin). To maintain the patient's blood oxygenation, oxygen was delivered using a facemask. Constant monitoring of oxygenation (pulse oximetry) and circulation (heart rate, continuous electrocardiogram and non-invasive blood pressure every $5 \mathrm{~min}$ ) was performed and temperature was assessed. Additionally, four pairs of transceiver electrodes were placed at the neck and the diaphragm level, delineating the thorax on both the patient's sides for the $\mathrm{Cl}$ measurements with the ICG (Solar ICG Module, 
GE). A beat-to-beat graphic analysis and the digital $\mathrm{Cl}$ values were displayed on a monitor.

The epidural anesthesia was performed with patients in the sitting position, most frequently in the L3L4 space (in the case of technical difficulties, L2L3 or L4L5). $2 \mathrm{ml}$ of $1 \%$ lidocaine (Lignocainum Hydrochloricum WZF 1\%, Polfa Warszawa SA) was infiltrated in the skin and subcutaneous tissue. The median approach was used for inserting the 18G Tuohy needle (Perifix, B. Braun) and the epidural space was identified with the loss of resistance technique. Three to four $\mathrm{cm}$ of epidural catheter was inserted cranially. Four $\mathrm{ml}$ of $2 \%$ lidocaine with norepinephrine (Lidocainum 2\% c. Noradrenalino $0.00125 \%$ WZF, Polfa Warszawa SA) was given for the test dose. The patient was placed in the supine position. If there were no signs of spinal or intravascular administration after $5 \mathrm{~min}$, a proper volume of a local anesthetic drug was given to achieve anesthesia level T7. Due to randomization, a nurse prepared a syringe earlier so she was the only one to know which local anesthetic was administered. Afterwards, the patient was placed in the lithotomy position and the first stage of the PNL began. For the second stage of the surgical procedure, the patient with the assistance of the personnel was placed in a prone position with the support of a pillow under the thorax, abdomen and pelvis.

The parameters evaluated in the study groups were: the variability of the $\mathrm{Cl}$ after changing the position to prone during PNL (measured with the ICG); the appropriateness of the epidural anesthesia technique for the PNL procedure measured by the number of participants having the procedure done completely with no need to interrupt since there was no hemodynamic instability or patient's discomfort; the effectiveness and adequate level of epidural anesthesia, evaluated with a loss of temperature feeling - where a T7 block level was considered as a success. The intensity of the motor blockade was judged with a modified Bromage score [7].

During the whole procedure, every $5 \mathrm{~min}$ blood pressure was measured non-invasively with an inflatable cuff placed around the upper arm. Continuous monitoring of the heart rate was performed as part of the electrocardiogram and pulse oximetry.
The authors analyzed the 20-minute period before and the 30-minute period after changing the position due to possible differences in duration of the procedure. There was significant variability in recorded values. For further comparisons following visual assessment of courses, parameterization was done. The $\mathrm{Cl}_{\text {before }}$ and the $\mathrm{Cl}_{\text {after }}$ are mean values of the data collected before and after turning prone. The $\mathrm{Cl}_{\text {decrease }} \%$ is the parameter that describes the percentage drop in the $\mathrm{Cl}$ after turning prone:

$$
\mathrm{Cl}_{\text {decrease }} \%=\frac{\mathrm{Cl}_{\text {before }}-\mathrm{Cl}_{\text {after }}}{\mathrm{Cl}_{\text {before }}} \times 100 \%
$$

\section{Statistical analysis}

Statistica 11.0 (StatSoft Poland Software) was used for statistical calculations. A statistically significant result is one in which the observed $p$-value is less than $<0.05$. While analyzing the correlation it was determined that the correlation coefficient varied from -1 (negative correlation) to +1 (positive correlation).

\section{Results}

The hemodynamic data collected from 45 patients were analyzed. In 5 cases, the electrodes were attached improperly after changing the position to prone or the data were not displayed on the monitor. Those patients were excluded from the analysis.

Forty-five patients investigated in both groups were comparable as regarded gender, ASA grade $\left(\chi^{2}\right.$ test) and body mass index (BMI) (Student's $t$-test). A slight but statistically significant difference in patients' mean age was observed ( $\chi^{2}$ test); $p$-value 0.03 (Table I).

A Cl decrease was recorded every time after changing the position from lithotomy to prone. The mean value of the $\mathrm{Cl}$ before changing the position was $2.96 \pm 0.43 \mathrm{l} / \mathrm{min} / \mathrm{m}^{2}$ and after turning prone the $\mathrm{Cl}$ dropped to mean $2.28 \pm 0.40 \mathrm{l} / \mathrm{min} /$ $\mathrm{m}^{2}$. The $\mathrm{Cl}_{\text {decrease }} \%$ was $22.58 \pm 11.47 \%$. The maximum decrease was $53 \%$, whereas the minimal one was $2.78 \%$; and in as many as 7 patients, the $\mathrm{Cl}$ drop was greater than 35\% (Figure 1).

The maximum decrease in the $\mathrm{Cl}$ value was usually observed after $10-15 \mathrm{~min}$. The $\mathrm{Cl}_{15}$ pa-

Table I. Patients' demographic and ASA classification

\begin{tabular}{|lccc|}
\hline Group & Bupivacaine $-\mathbf{M}(\boldsymbol{N}=\mathbf{2 4})$ & Ropivacaine $-\mathrm{R}(\boldsymbol{N}=\mathbf{2 1})$ & $\boldsymbol{P}$-value \\
\hline Gender, female/male & $10 / 14$ & $9 / 12$ & 0.93 \\
\hline ASA 1/ASA 2 & $9 / 15$ & $9 / 12$ & 0.71 \\
\hline Age, mean \pm SD & $55.3 \pm 11.4$ & $47.2 \pm 13.3$ & 0.03 \\
\hline BMI, mean \pm SD & $28.2 \pm 3.1$ & $27.9 \pm 4.6$ & 0.77 \\
\hline
\end{tabular}

ASA physical status classification - American Society of Anesthesiology physical status classification, BMI - body mass index. 


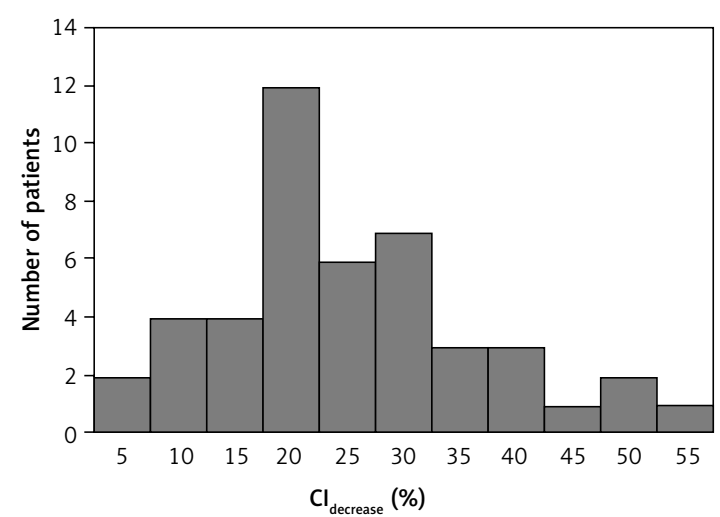

Figure 1. Percentage drop in cardiac index $(\mathrm{Cl})$ after changing to prone

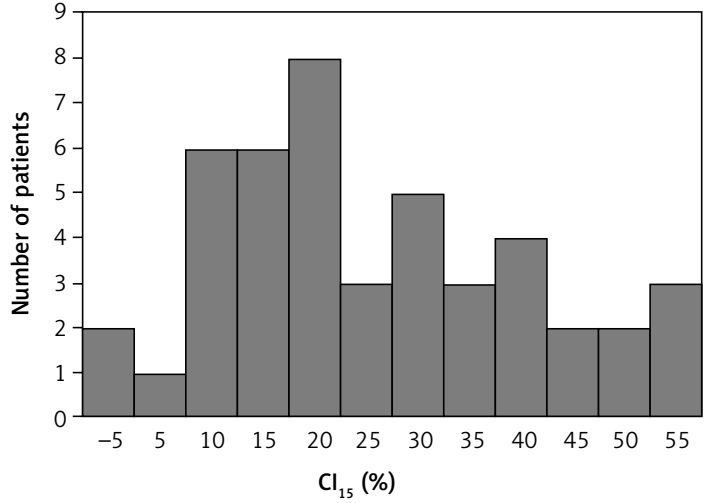

Figure 2. Percentage drop in $\mathrm{Cl} 15$ min after changing to prone

Table II. Decrease in $\mathrm{Cl}$ in randomization groups

\begin{tabular}{|lccc|}
\hline Drop of $\mathrm{Cl}$ & $\begin{array}{c}\text { Group } \\
\mathrm{R}(\boldsymbol{N}=21)\end{array}$ & $\begin{array}{c}\text { Group } \\
\mathbf{M}(\boldsymbol{N}=24)\end{array}$ & $\boldsymbol{P}$-value \\
\hline $\mathrm{Cl}_{\text {decrease }} \%$ & $22.38 \pm 10.47 \%$ & $22.75 \pm 12.51 \%$ & 0.91 \\
\hline $\mathrm{Cl}_{15}$ & $20.66 \pm 14.89 \%$ & $26.28 \pm 15.32 \%$ & 0.22 \\
\hline
\end{tabular}

Cl-cardiac index.

rameter was counted for all participants. The mean value of the drop was $23.66 \pm 15.22 \%$ (min: $-3.57 \%$, max: $54.28 \%$ ) (Figure 2).

The $\mathrm{Cl}_{\text {decrease }} \%$ and $\mathrm{Cl}$ 15 parameters were compared between the randomization groups. The mean drop was similar but slightly deeper in group $M$. The difference was not statistically significant (Table II).

No correlation was observed either between the decrease in the $\mathrm{Cl}$ and the age, gender, ASA 1-2 or BMI. N - normal body weight (BMI 18.5-24.9 kg/ $\mathrm{m}^{2}$ ); Ov - overweight (BMI 25.0-29.9 $\left.\mathrm{kg} / \mathrm{m}^{2}\right) ; \mathrm{Ob}$ - obesity (BMI - 30.0-39.9 kg/m²). The change in the $\mathrm{Cl}$ depending on the body weight and the ASA grade was also analyzed across the groups ( $\mathrm{Ta}$ ble III). The results were not statistically significant.

The correlation between the $\mathrm{Cl}$, mean arterial blood pressure and heart rate was negative.

The mean amount of fluids administered intraoperatively was similar in both groups - $19.9 \mathrm{ml} /$ $\mathrm{kg}$ (group M) vs. $20.1 \mathrm{ml} / \mathrm{kg}$ (group R). The TFC parameter (thoracic fluid content) was observed

Table III. Mean drop of $\mathrm{Cl}$ in ASA grade 1 and 2 patients, depending on BMI

\begin{tabular}{|lccc|}
\hline ASA & BMI & $N$ & $\mathrm{Cl}_{\text {decrease }} \%$ \\
\hline 1 & $\mathrm{~N}$ & 11 & $24.19 \pm 9.62$ \\
\hline 1 & Ov & 4 & $16.61 \pm 2.54$ \\
\hline 1 & Ob & 3 & $12.96 \pm 5.15$ \\
\hline 2 & $\mathrm{~N}$ & 13 & $21.80 \pm 10.66$ \\
\hline 2 & Ov & 6 & $23.17 \pm 17.57$ \\
\hline 2 & Ob & 8 & $27.77 \pm 13.15$ \\
\hline
\end{tabular}

BMI: normal (N), overweight (Ov), obesity $(\mathrm{Ob})$ on the monitor. Its value was stable during the observation period. Changing the position of the patient did not influence this parameter, so there was no statistical correlation between TFC and the decrease in $\mathrm{Cl}$.

All 50 patients had the PNL performed without complications. None of them reported discomfort in the prone position. The level of the anesthesia was satisfactory as no patient felt pain during the procedure. The time between epidural administration of local anesthetic and starting the first stage of the PNL procedure was $20 \mathrm{~min}$. Changing the position to prone occurred not earlier than $30 \mathrm{~min}$ after the drug administration so the level of anesthesia was already stable. The intensity of the motor blockade was subtly different. All patients were scored as either Bromage 4 (88\% in group $M)$, i.e. detectable weakness of hip flexion while supine (full flexion of knees), or Bromage 5 (80\% in group R), i.e. no detectable weakness of hip flexion while supine.

\section{Discussion}

This study has confirmed that the $\mathrm{Cl}$, measured with ICG, decreases after changing the position to prone during PNL. To our best knowledge, the evaluation of the decrease in the cardiac output during PNL or during epidural anesthesia in the prone position has not been reported in the literature. Nonetheless, the results are similar to those presented by other authors evaluating hemodynamic changes observed during neurosurgical operations under general anesthesia. Already in 1985, in 16 patients with cardiopulmonary dis- 
ease during neurosurgery in the prone position Backofen and Schauble [8] observed an average decrease in the $\mathrm{Cl}$ of $24 \%$ (from $2.71 \pm 0.52$ to 2.05 \pm 0.40 ) with a small change in the heart rate and maintained mean arterial pressure. Further studies confirmed that. Yokoyama et al. [9] evaluated 21 patients with direct pulmonary artery pressure (PAP) or inferior vena cava (IVC) pressure monitoring, and reported a decrease in the $\mathrm{Cl}$ of $20 \%$ (from $3.1 \pm 0.5$ to $2.5 \pm 0.3$ ) in the prone position with a convex saddle frame and no changes in the $\mathrm{Cl}$ in the flat prone position during lumbar surgery. It is suggested that the position of the heart at a hydrostatic level above the head and limbs may cause reduced venous return to the heart and, consequently, a decreased $\mathrm{Cl}$. The decrease in the $\mathrm{Cl}$ could also be attributed to increased intra-thoracic pressures causing a decrease in arterial filling, leading to an increase in sympathetic activity via the baroreceptor reflex [10].

Undoubtedly, epidural anesthesia may cause a decrease in the $\mathrm{Cl}$ even of $10 \%$ [11] due to a sympathetic block. Nevertheless, it should be noted that the onset of data collecting for the analysis was 20 min before changing the position. During that time the first stage of PNL took place, the anesthesia level was set and the hemodynamic parameters were normal.

Although in most centers PNL is performed under GA, in the present study, we proved that the procedure could be performed safely under epidural anesthesia. All participants had the procedure done completely with no need to interrupt in fear of hemodynamic instability or patient's discomfort. The use of lower concentrations of local anesthetics $(0.25 \%$ bupivacaine and $0.2 \%$ ropivacaine) combined with opioids provided excellent analgesia with minimal motor block. An anesthesia level of T7 necessary for PNL was achieved every time. According to the Bromage score of 4-5, all the participants were able to self-position for the procedure and turned from lithotomy to prone with a little assistance of the personnel.

Local anesthetic agents can influence the cardiac contractility. Direct myocardial actions comprise negative chronotropic, dromotropic and inotropic effects. A collapse, even death, may occur after intoxication with amide local anesthetic agents. The lower lipophilicity of ropivacaine versus bupivacaine correlates with lesser cardiodepressant effects [12]. Scott et al. [13] proved that neither ropivacaine nor bupivacaine influences the $\mathrm{Cl}$ after intravenous administration. The decreased $\mathrm{Cl}$ after turning prone occurred irrespective of the type of local anesthetic used in the study and did not correlate with patients' age, gender, or ASA physical status grade 1-2.

The variability in the $\mathrm{Cl}$ was not correlated with the BMI either. That might seem surprising, but
Brown et al. [14] proved that ICG is a good method for assessment of cardiac performance in obese patients, and Stelfox et al. [15] after examining 700 adults stated that variations in the BMI translate into predictable but only modest differences in the CO and the SV, even at the extremes of body size. He concluded that body habitus should not appreciably complicate the interpretation of hemodynamic measurements.

Cardiac index monitoring with ICG proved to be a good choice for the present study. Ninety percent of the data collected from participants had no artefacts and could be analyzed. Piechota et al. [6] reported the quality of ICG $\geq 70 \%$ in $53.91 \%$ of the measurements and $\geq 30 \%$ in $88.28 \%$ of the measurements among the septic patients.

A non-invasive method is a limitation itself. The older studies suggested that the overall agreement of ICG with established reference methods was poor. The technology has been re-evaluated and recently several studies revealed promising results [16]. There is no need to place either a central venous catheter or an arterial catheter to measure the hemodynamic parameters. An arterial line is necessary to measure the $\mathrm{Cl}$ in minimally invasive methods as they are based on continuous arterial pulse-wave analysis. Although some authors find ICG to be a reliable method for determining absolute values of the $\mathrm{Cl}$, others reserve this method to measure only the changes of this parameter [17]. Therefore, in our study, to avoid the use of controversial absolute values of the hemodynamic parameters, it was only the changes that were analyzed.

The study was also limited by the fact that the groups were small. Therefore, it should be treated as a preliminary report. Only ASA grade 1 and 2 patients were included; therefore, they had no serious comorbidities. Although there were no statistically significant differences between the $\mathrm{Cl}$ decrease and the ASA grade and good circulatory compensation was proved, for patients with the ASA physical status grade 3 further studies should be conducted. Those patients have one or more moderate to severe diseases (e.g. poorly controlled diabetes mellitus or hypertension, alcohol dependence, implanted pacemaker). Special precaution should be taken for patients with congestive heart failure as they usually have lower values of $\mathrm{Cl}$ [18]. According to the EAU guidelines, both the prone and the supine positions are equally safe for performing PNL. The authors suggest considering an additional cardiologic workup or the supine position for PNL in ASA grade 3 patients to exclude the risk of circulatory decompensation after being placed in the prone position.

The conducted analysis allows us to formulate the following conclusions: during PNL the change from the lithotomy to the prone position results in a decrease in the $\mathrm{Cl}$. Lumbar epidural anesthe- 
sia ensures adequate analgesia for PNL and has the advantage of patient's self-positioning for the surgery. A decrease in the $\mathrm{Cl}$ should be taken into consideration during qualification for PNL in the prone position. Impedance cardiography as non-invasive hemodynamic monitoring is an effective method of obtaining data in patients undergoing surgery in the prone position.

\section{Conflict of interest}

The authors declare no conflict of interest.

\section{References}

1. Türk C, Knoll T, Petrik A, et al. EAU Guidelines on urolithiasis. April 2014, Available at: http://uroweb.org/ wp-content/uploads/22-Urolithiasis_LR_full.pdf; limited update March 2015.

2. Nandanwar AS, Patil Y, Wagaskar VG, Baheti VH, Tanwar HV, Patwardhan SK. A comparison of efficacy of segmental epidural block versus spinal anaesthesia for percutaneous nephrolithotomy. J Clin Diagn Res 2015; 9: UCO1-4.

3. Hu H, Qin B, He D, et al. Regional versus general anesthesia for percutaneous nephrolithotomy: a meta-analysis. PLoS One 2015; 10: e0126587.

4. McCoy JV, Hollenberg SM, Dellinger RP, et al. Continuous cardiac index monitoring: a prospective observational study of agreement between a pulmonary artery catheter and a calibrated minimally invasive technique. Resuscitation 2009; 80: 893-7.

5. Lavdaniti M. Invasive and non-invasive methods for cardiac output measurement. Int I Caring Sci 2008; 1: 112-7.

6. Piechota M, Irzmanski R, Banach M, Kowalski J, Pawlicki L. Impedance cardiography in haemodynamic monitoring of septic patients: a prospective study. Arch Med Sci 2007; 3: 145-51.

7. Breen TW, Shapiro T, Glass B, Foster-Payne D, Oriol NE. Epidural anesthesia for labor in an ambulatory patient. Anesth Analg 1993; 77: 919-24.

8. Backofen JE, Schauble JF. Hemodynamic-changes with prone positioning during general-anesthesia. Anesth Analg 1985; 64: 194.

9. Yokoyama M, Ueda W, Hirakawa M, Yamamoto H. Hemodynamic effect of the prone position during anesthesia. Acta Anaesthesiol Scand 1991; 35: 741-4.

10. Edgcombe H, Carter K, Yarrow S. Anaesthesia in the prone position. Br J Anaesth 2008; 100: 165-83.

11. Brull R, MacFarlane AJR, Chan VWS. Spinal, epidural and caudal anesthesia. Physiologic effects. Cardiovascular. Stroke. In: Anesthesia. $8^{\text {th }}$ ed. Miller RD, Eriksson LI, Fleisher L, Wiener-Kronish JP, Cohen NH, Young WL (eds). Saunders, Philadelphia 2015; 1689.

12. Kuthiala G, Chaudhary G. Ropivacaine: a review of its pharmacology and clinical use. Indian J Anaesth 2011; 55: 104-10.

13. Scott DB, Lee A, Fagan D, Bowler GMR, Bloomfield P, Lundh R. Acute toxicity of ropivacaine compared with that of bupivacaine. Anesth Analg 1989; 69: 563-9.

14. Brown CVR, Martin MJ, Shoemaker WC, et al. The effect of obesity on bioimpedance cardiac index. Am J Surg 2005; 189: 547-50.

15. Stelfox HT, Ahmed SB, Ribeiro RA, Gettings EM, Pomerantsev E, Schmidt U. Hemodynamic monitoring in obese patients: the impact of body mass index on cardiac output and stroke volume. Crit Care Med 2006; 34: 1243-6.

16. Saugel B, Cecconi M, Wagner JY, Reuter DA. Noninvasive continuous cardiac output monitoring in perioperative and intensive care medicine. $\mathrm{Br} J$ Anaesth 2015; 114 562-75.

17. Koźluk E, Cybulski G, Piątkowska A, et al. Early hemodynamic response to the tilt test in patients with syncope. Arch Med Sci 2014; 10: 1078-85.

18. Carlsson M, Andersson R, Bloch KM, et al. Cardiac output and cardiac index measured with cardiovascular magnetic resonance in healthy subjects, elite athletes and patients with congestive heart failure. J Cardiovasc Magn Reson 2012; 14: 51. 